Res Pública Revista de Historia de las Ideas Políticas

ISSN: 1131-558X

http://dx.doi.org/10.5209/rpub.70459

\title{
N. Sánchez Madrid y L. Alegre Zahonero (coords.), Territorios por pensar. Un mapa conceptual para el siglo XXI, Madrid, Siglo XXI, 2019, 252 pp.
}

Juan Mayorga afirmaba en 581 mapas que lo que "la gente busca en un mapa es que les diga la verdad". Si bien elaborar mapas puede resultar arduo, ello no debe escamotear el compromiso por asumir dicha tarea. Un mapa nos permite expresarnos a nosotros mismos en relación con el mundo. Es la condición de posibilidad de todo decir pues siempre hablamos desde algún lugar. Sin mapa de referencia "muchos intentan decir cosas que nunca han podido decir". El cartógrafo debe actuar como "el traductor" para esas personas. Siguiendo a Alberto Sucasas, la tarea que subyace a la elaboración de mapas es la de "humanizar la intemperie"2. Y si hay una idea que alumbra el esfuerzo contenido en Territorios por pensar. Un mapa conceptual para el siglo XXI, trabajo coordinado por Nuria Sánchez Madrid y Luis Alegre Zahonero, es sin lugar a dudas esta. La obra desempeña una labor cartográfica sobre las zonas invisibilizadas que mantienen a la intemperie a las subjetividades no reconocidas por las coordenadas conceptuales tradicionales. En este sentido, se concibe la filosofía como "un saber limítrofe: se nutre de los límites al mismo tiempo que los alimenta" (pp. 74-75). Se trata tanto de abordar las sombras de la realidad, como de permitir que esas regiones creen nuevos marcos discursivos en el seno del pensamiento. Este es uno de los problemas que denuncia la obra, ya que si nuestros mapas tienen tantas lagunas es porque "al adentrarnos en el bosque filosófico de los grandes interrogantes, enseguida descubrimos que la gama de preguntas está bien delimitada y que los temas oficialmente importantes ya han sido previamente acordados" (p. 119). Territorios por pensar reivindica la importancia de abrir sendas inexploradas $-\mathrm{o}$ no tan transitadas-.

Un territorio es un espacio físico e institucional donde impera un "ius terrendi epistemológico y político [que asegura la] continuidad entre mundo, mirada y pensamiento que llamamos «realidad»" (p. 75). Es preciso abordar los elementos de esta continuidad para explorar las potencialidades de cambio hacia nuevas cartografías más inclusivas con las subjetividades no localizadas y menos dañinas con las ya reconocidas. Para comprender la configuración del ius terrendi la primera parada son las NORMAS (Jesús González Fisac). Siguiendo el análisis foucaultiano, con algún eco de Canguilhem, la

J. Mayorga, 581 mapas, 2011 [Disponible en: https://wp.nyu.edu/ gsas-revistatemporales/juan-mayorga-581-mapas/]

2 Ensayo contenido en J. Mayorga, El cartógrafo, Segovia, La uña rota, 2017, p.108. Cabe mencionar que el aporte de Laura Herrero Olivera se estructura explícitamente sobre este drama de Mayorga. "función de la norma es «fabricar sociedad»" (p. 23), diferenciando entre lo normal y lo patológico. La creación de la norma no es neutral. Establece qué debe considerarse amistoso y qué será tomado por extraño, siendo esto no solo el enemigo allende nuestras fronteras, sino también lo que dándose en el seno del territorio se considera una desviación. El objetivo de la norma es hacer "previsible en su conducta" (p. 35) a los sujetos, volviéndolos gobernables, lo cual requiere tanto de vigilancia externa como de la interiorización de una pauta de conducta por parte de los sujetos -"el gobierno de la conducta" (p. 25)-. No es preciso insistir en el poder que ostenta el neoliberalismo para determinar el horizonte de conductas aceptables.

Ampliar este horizonte pasa por averiguar en qué consisten las ANDANZAS (Sandra Santana Pérez) del ser humano. Aquí Jakob von Uexküll trabaja junto a Rafael Sánchez Ferlosio. El punto de partida es que cada animal limita su mundo en función de sus capacidades perceptivas. Pero mientras que los animales reciben pasivamente la significación que delimitará su Umwelt, los seres humanos podemos llevar a cabo una suspensión de sentido que, mediante el lenguaje, nos habilita a comprender un mismo objeto a través de un amplio abanico de posibilidades. Esto nos acredita como "observadores neutrales" (p. 59), a pesar de lo cual en la mundanidad de la vida las cosas "no aparecerían ante nosotros desprovistas de sentido" (p. 60). Este sentido no se limita a aparecer, sino que depende de lo que "deseamos ver" (p. 67), pudiendo caer en una "ceguera momentánea" (p. 68), en la que no vemos algo simplemente porque no esperamos encontrarlo ahí. ¿No es este un efecto relevante para el plan de cartografiado? Si una imagen de demanda puede cegar cierto punto de la realidad, entonces el mapa confunde más que ayuda. Las imágenes de demanda "pueden modificarse" (p. 69, nota), por lo que habrá que trabajar para ver más en lugar de menos. Y tras las andanzas nos asentaremos en HÁBITATS (Ana Carrasco Conde) donde no solo sobrevivir, sino "vivir bien" (p. 41). Nacemos siempre en un contexto: el "espacio de nuestro habitar es el espacio de nuestro decir, pero ¿qué hacer cuando vivimos en un decir que no es el nuestro?" (p. 48). Bien puede ocurrir que el ius terrendi del decir natal no resulte acogedor. En tal caso el hábitat se convierte en "una habitación "propia» en casa ajena [que] aunque forma parte del hábitat, es inhóspita" (p. 42). Pensar los hábitats se vuelve "una manera de hacer lugar, es decir, una política" (p. 41) que busque desquiciar el lenguaje -ya que no podemos deshacernos 
de él, ni seguir hablando igual- con la esperanza de generar nuevos "lugares de inclusión" (p. 54).

Para entender nuestro hábitat hay que atender a las MIRADAS (Antonio de Murcia Conesa). Lo primero que vemos es que el sujeto está dislocado, pues su autopresencia "es imposible y el desplazamiento de la mirada hacia un punto de vista externo es necesario" (p. 81). Hoy es fácil situar esta dislocación en las cámaras, cuyo claro correlato son las pantallas donde "se confunden la sublimada mirada excorpórea y la subjetiva mirada espectadora" (p. 85). De suerte que en ningún presente como en el nuestro se ha mirado tanto y, a la vez, tanto ha angustiado ser mirado. No es para menos cuando "la mirada al otro que me mira no puede esquivar la responsabilidad" (p. 89), ya que solo a través del otro "el rostro propio pierde, al saberse visto, la opacidad que tiene para sí" (ibidem). Por otro lado, la sobrexposición señalada pasa factura en general a nuestras SENSACIONES (Jordi Massó Castilla). El aluvión constante de sensaciones pretende esconder la pobreza de experiencia que campa hoy día, como denunciara Pessoa. Aunque en un inicio el arte trató de canalizar dicho exceso para combatir la falta de experiencia, pronto esta estrategia se descubriría concordante con un capitalismo de consumo ininterrumpido. Así, el espíritu emancipatorio original mutó en una sensología: un fluir de sensaciones "tan intenso y abundante como uniforme e inane" (p. 102), hipertrofiando nuestra facultad sensitiva que termina por "desconectarse de la reflexiva" (ibidem). Ante tal panorama, ambos capítulos convergen en su respuesta: apostar por un marco comunitario distinto, con "una mirada sin dueño" (p. 90), donde el sentimiento se hermane de nuevo a la reflexión gracias al cultivo de un "sentir común" (p. 103) no enajenado.

La posibilidad de modificar las imágenes de demanda que vimos en $A N D A N Z A S$ se entrelaza con la apuesta de MIRADAS y SENSACIONES en el siguiente capítulo, ya que para cambiar la forma en que miramos y sentimos, abriéndonos a puntos ciegos ocultos hasta ahora, es menester pensar las PEDAGOGÍAS (Laura Herrero Olivera). A partir de una comparativa entre la pedagogía de Kant y las que surgen en la primera mitad del s. $\mathrm{XX}$, recordamos que la meta de la pedagogía "es que el niño aprenda a pensar" (p. 111). Pensar tiene que ver con acostumbrar la imaginación del niño a desarrollarse dentro de un marco de reglas, para así no estar desocupada, pero sin extraviarse en fines quiméricos. El símil cartográfico surge solo: "En un territorio por pensar conocer el mapa de lo caminado doma nuestro deseo de encontrar fines imaginarios. Sometida a reglas, pero sin estar desocupada, es decir, dando cabida a la imaginación, se aprende algo cuando se usa el mapa" (p. 108). Al buscar que el niño se oriente mediante el desarrollo de sus propias facultades, en territorios conocidos y en los que están por pensar, la pedagogía muestra su potencial subversivo haciendo cuestionar constantemente las fronteras del "sistema existente" (p. 118).

Territorios por pensar ofrece varios ejemplos de fronteras a alcanzar. Tal vez la más destacada sean las DANZAS (Ibis Albizu), pues como protestaba Francis Sparshott, sorprende el desprecio filosófico hacia ella cuando "es nada más y nada menos que una de las siete bellas artes" (p. 121). Responder a este prejuicio nos lleva a replantear otro: la mala relación entre pensamiento y movimiento. Lejos de ser irreconciliables, la filosofía griega se interesó ampliamente por la esencia del movimiento. Fue especialmente relevante la geometría por traducir al logos el espacio físico. Haríamos bien entonces en pensar la danza como una "geometría física capaz de transmitir la más pura afección humana" (p. 130) que hay tras nuestros movimientos. Además del abordaje teórico, las danzas han "logrado bailar la pregunta por el movimiento, [escenificando] la clave que dio origen a la filosofía" (p. 131). Otra frontera desbloqueada son los ENGRANAJES (Antonio Dopazo Gallego) de la experiencia temporal, abordada, nuevamente, desde la quiebra: el déjà vu. Siguiendo a Bergson, el déjà vu es un "salto del mecanismo de acople entre recuerdo y percepción" (p. 145). Esto es así porque "la formación del recuerdo nunca es posterior a la de la percepción" (p. 138). De modo que el instante presente está escindido en dos procesos simultáneos. Tal escisión supone la inserción en la temporalidad, donde "el pasado no vuelve a la conciencia sino en la medida en que puede ayudar a comprender el presente y prever el porvenir" (p. 141). En esta medida, posibilita la "creación de novedad" (p. 140), esto es, la libertad. O de otro modo, la acción libre acontece en el cosmos gracias a que el flujo temporal no está escrito en piedra, sino que cada instante presente es afectado de una forma por el pasado, dando lugar a una u otra proyección hacia el futuro, convirtiéndonos en "explorador[es] de la acción" (p. 141) cada vez. ¿No sería Tiempo desarticulado, de Philip K. Dick, un ejemplo novelado perfecto de cómo el déjà vu revela la estructura funcional de la experiencia a través de los engranajes que saltan y distorsionan el presente?

Territorios por pensar también se cuestiona sobre el hecho mismo de territorializar el pensamiento. Si solo concebimos el mundo en territorios, ¿qué sucede con lo que, por pertenecer a más de un lugar, no pertenece a ninguno? Son las HIBRIDACIONES y los MONSTRUOS. HIBRIDACIONES (Amanda Núñez García) afirma que cualquier límite es un criterio externo que separa, mientras que la hibridación es "una fuerza interna que se despliega y se extiende en el espacio al vivir" (ibidem), haciendo porosa la dicotomía "fuera y dentro". A pesar de que la hybris comprende mejor la vida en su conjunto -"estamos rodeados y somos híbridos" (p. 161)-, en las prácticas concretas introducimos "subrepticiamente esta dicotomía una y otra vez" (p. 161). La insistencia en no reconocer el valor ontológico a las hybris solo consigue que a la larga irrumpan "de modo traumático" (p. 165), haciendo del cuidado de la hybris un asunto de estabilidad social. Pese a todo, estas irrupciones serán interpretadas como estallidos $e x$ nihilo, ajenas a la opresión sistémica, que serán analizadas por especialistas para atestiguar su excepcionalidad. Latour bautizó este paradigma como "cajanegrización" (p. 165). Desde este paradigma, "de los híbridos rápidamente se pasó a los monstruos" (p. 156), pues estos, como leemos en MONSTRUOS (Guillermo de Eugenio Pérez), son "la excepción que confirma la regla" (p. 172) 
-tema ya insinuado en NORMAS-. Este capítulo expone que la represión de las hybris siempre responde a un determinado marco epistemológico, incluso en las ciencias naturales. El marco epistemológico no solo establece la conformidad de la regla, sino que también fija qué es una excepción legítima y a qué ni siquiera se considera una desviación posible. La estigmatización de los monstruos responde a la arbitrariedad de la norma investigadora. A este respecto resulta esclarecedora la intervención de Maupertuis en los debates sobre embriología del s. XVIII, quien protestó por que se tachase a los licántropos de monstruos imposibles, mientras que se aceptaba la cuestionable existencia de "niños-fruta". La causa era la mentalidad cristiana dominante. La doctrina del pecado original heredado casaba con la posibilidad de que los malos hábitos de la madre fuesen heredados, traduciéndose en el castigo dismorfizante sobre el feto. Por contra, aceptar la licantropía suponía reconocer poder engendrador al diablo, lo que no convenía a la iglesia. Como subrayó Maupertuis, es "la imaginación desbocada del investigador" la que define los monstruos (p. 181). Si el progreso científico consiste en dar con la "metáfora adecuada" (p. 183) para leer el mundo, una que no acarre tantos prejuicios, ¿hasta qué punto sigue siendo útil una metáfora que estigmatiza las hybris y los monstruos en nuestra realidad mestiza?

Igual que hay metáforas que lastran, hay marcos conceptuales que potencian la exploración. Un ejemplo son las SEXUALIDADES (Luis Alegre Zahonero). En cierta medida, este capítulo recoge el guante lanzado por HÁBTITATS de desquiciar el lenguaje. Las palabras no se limitan a "describir nuestra vida, [sino a] prescribirnosla" (p. 189). El objetivo no es deshacernos del lenguaje -que haría imposible "saber siquiera quiénes somos" (p. 191) -. Es comprender su maleabilidad para forjar conceptos en los que identificarnos, sin hacer de ellos una "una mazmorra de la que no nos podemos mover" (ibidem). Las sexualidades LGTBIQ son emblemáticas de un uso emanciptorio del lenguaje, pues son "menos dadas a convertir su «identidad» en una mazmorra, y, con ello, vuelven más finos y manejables los barrotes de las jaulas de todxs" (p. 194), logrando una realidad menos asfixiante. Por otro lado, la reflexión sobre los GÉNEROS (Clara Navarro Ruiz) también es punta de lanza en la navegación interterritorial. El actual sistema homogeniza las identidades bajo el marco de la razón maximizadora del beneficio. Mas no es un secreto que esto oculta el privilegio de un tipo de subjetividad sobre los demás, el "«BBVAh» (blanco-burgués-varón-adulto-heterosexual” (p. 206). Los géneros, en la medida en que "resiste[n] incólume[s] a la visión totalizadora" (p. 203), se resuelven un arma de batalla contra esto. Uno de los grandes aciertos del feminismo -tras una autocrítica sobre su versión hegemónica- fue articularse en torno a la noción de interseccionalidad, que busca comprender "los distintos ejes de opresión que someten a las personas, sin jerarquizarlos" (p. 208). Aplicándola sobre muy diversos ámbitos -economía, derecho, biología...-consigue destapar el entramado de opresiones subyacente al sistema, no solo por interés teórico, "sino como condición de posibilidad para la transformación social" (p. 209), tarea en la que el surgimiento de los estudios queer desempeñó un papel crucial. Se suma GÉNEROS así a los esfuerzos del resto de capítulos, apostando por un discurso que "vaya al ritmo de la realidad, necesariamente cambiante" (p. 215), rechazando las unificaciones opresoras, recordando que los géneros -igual que la vida- son aun "territorio por explorar" (p. 214).

La obra cierra pensando sobre los MALESTARES (Nuria Sánchez Madrid). Ante todo, se trata de señalar que aquello que el neoliberalismo se ufana en achacar al fracaso personal responde, principalmente, a una desatención sistémica de los sujetos, siendo este el verdadero origen del malestar. La base para esto es el "desdibujamiento de las fronteras entre vida privada y pública" (p. 219). Lo que se persigue es imponer sobre los elementos tradicionalmente ajenos a la esfera del trabajo una lógica en la que todo valor se reduzca a una cuantificación estadística. Con Dejours, esta lógica se sintetiza en la noción de "factor humano" (p. 220). A partir de ella, en la evaluación de toda interacción social-ocio, cuidados, seguridad...- primará el carácter estadístico de la calidad de vida, ocultando la esencia cualitativa de la opresión, dando lugar a situaciones en las que, por ejemplo, el estatus económico de una persona LGTBIQ "no le salvaguarde de recibir los golpes secos de una sociedad heteronormativa" (p. 224). El problema se intensifica cuando la exigencia de justicia sucumbe a esta concepción abstracta del malestar, dando por hecho que todos los sujetos parten de una situación formal equiparable, sin prestar "atención a las circunstancias en que se encuentran los diferentes grupos sociales y sus rasgos sociológicos" (p. 228), de tal modo que bastaría con reequilibrar los medidores estadísticos de calidad de vida. Una respuesta así, aunque bienintencionada, mantiene ocultas las fuentes auténticas del malestar. En definitiva, Territorios por pensar acepta el órdago de un mundo cambiante y actualiza sus discursos para estar a la altura de un presente que ya no se deja cartografiar por coordenadas obsoletas. Todo un ejemplo de perennidad filosófica.

Enrique García Otero 